\title{
Chapter 14 \\ Promoting Effective Biosecurity \\ Governance: Using Tripwires to Anticipate and Ameliorate Potentially Harmful Development Trends
}

\author{
Benjamin D. Trump, Stephanie Galaitsi, Miriam Pollock, Kaitlin M. Volk, \\ and Igor Linkov
}

\subsection{Introduction}

Synthetic biology is a new, rapidly growing interdisciplinary field which seeks to use engineering techniques to alter and construct new biological components, devices, and systems. The rate of synthetic biology development and research has increased over the past two decades in both industry and academia (Ahteensuu 2017). Applications include medicine (new vaccines, delivery of therapeutics, and treatments), energy (biofuels), environmental remediation, food production, and general industry (detergents, adhesives, perfumes) (Evans and Selgelid 2015; Gronvall 2015). While synthetic biology heralds advances in these fields, its techniques could also be adapted for malicious purposes and used by terrorist organizations, rogue actors, or hostile nations to create dangerous pathogens, invasive organisms, or other disruptive biological agents (Yeh et al. 2012). Such potential makes synthetic biology a dual-use research area of concern (DURC) as the same techniques can be used to benefit or harm people, animals, environments, technology, or nations (Getz and Dellaire 2018). To cope with threats arising from synthetic biology's dual-use nature, biosecurity is needed to prevent, detect, and attribute biological attacks.

The rapid development of synthetic biology is lowering barriers to access its technological capabilities. While organizations seek to develop and formalize effective governance strategies for managing the technology's risks to humans and the environment, an increasing number of independent actors are engaging in the technology (Trump et al. 2020). Existing biosecurity policy practices have left gaps in biosecurity effectiveness for synthetic biology. Such gaps require an iterative

B. D. Trump $(\bowtie) \cdot$ S. Galaitsi $\cdot$ M. Pollock $\cdot$ K. M. Volk $\cdot$ I. Linkov

US Army Corps of Engineers, Concord, MA, USA

e-mail: Benjamin.D.Trump@usace.army.mil 
response to influence countries and organizations away from harmful or nefarious synthetic biology research applications.

In biosecurity, triggering mechanisms that signal when a nation, sub-state actor, or individual is on the path towards biological weapons development and deployment can be part of this response. These mechanisms, called tripwires, are actions, events, or breakthroughs that impel a country toward either enabling or moving away from biosecurity threats. They can include both bottom-up and top-down signals. Bottom-up tripwires include information hazard (the release of information by an individual, company, or academic institution that could be used by a malicious actor), profit motivation, and partnership with entities of biosecurity concern (whether low or high). Top-down tripwires also include information hazard, as well as internal or external conflict that could motivate a nation to develop and use biological weapons to maintain power, a public health crisis that could cause biosecurity and biosafety regulations to be relaxed in search of a treatment or cure, and geopolitical alignment with a nation of some degree of biosecurity concern.

\subsection{Biological Weapons in History}

Biological weapons have been used since ancient times. These ancient weapons included scorpion bombs (terracotta pots filled with deadly scorpions and thrown at the enemy), crushed toxic hellebore plants, and arrows tipped with poison (Mayor 2003). As states sought new ways to generate advantages over their opponents, they developed increasingly advanced biological weapons. In 1925, in large part as a response to the devastating use of chemical and biological weapons in World War I, the Geneva Protocol was passed, banning the usage of biological and chemical weapons in wartime. Nevertheless, many states continued their biological weapons programs. During World War II, for instance, Japanese units deployed bombs filled with plague-ridden fleas in China as a part of their biological weapons program.

In 2001, in the worst biological attack in US history, letters laced with Bacillus anthracis spores, or anthrax, were sent through the U.S. Postal Service (DOJ 2010). The so-called "Amerithrax" bioterror attack resulted in five deaths, 22 infections, the prophylaxis of over 30,000 people, and hundreds of millions of dollars in decontamination expenses, as well as around $\$ 6$ billion in lost revenue and new security measures (DOJ 2010). After a lengthy investigation, it was determined that one man, acting alone, had been responsible for the attack. This illustrates the enormous destructive potential of bioweapons (FBI n.d.; Ellis 2014).

Many countries, including the US, UK, and Russia, were developing biological and chemical agents for warfare until the Convention on the Prohibition of the Development, Production and Stockpiling of Bacteriological (Biological) and Toxin Weapons and on Their Destruction was signed in 1972 ("BWC"). Since 1970, there have been 35 confirmed cases of biological weapon deployment (Franconi et al. 2018), with the majority of research and weapons production being pursued by state actors. However, synthetic biological weapons are expected to become a larger 
concern as the field advances and as malicious sub-state or non-state actors pursue and adopt these weapons (Gronvall 2018).

For almost 50 years, the BWC has been the gold standard for watching for and preventing state-sponsored biological weapons. However, advancements in synthetic biology have decreased the time, money, and skill needed for an individual or organization to participate in the field, leading to the development of pathogens by smaller sub-state and non-state actors who are not restricted by the BWC (Evans and Selgelid 2015). Some interested individuals and small companies interested in synthetic biology have set up labs in their homes using household items and equipment or kits ordered over the internet in a movement now known as "DIY Bio" or "garage biology" (Ledford 2010). Additionally, while chemicals have a set structure and formula that makes them easier to identify and govern, advancements in synthetic biology allow for the creation of novel types of biological weapons that are not explicitly prohibited by the BWC but instead exist in a sort of "gray zone." This increased accessibility of synthetic biology and difficulty in categorizing synthetic biology products creates a threat space that is not fully captured within the structure or implementation of the BWC.

Synthetic biology raises the possibility that pathogenic bioweapons could be designed, developed, and deployed in new ways that diverge from the diseasecausing characteristics of naturally occurring pathogens. Traditionally, only known pathogens found naturally in the environment, such as B. anthracis and Y. pestis, were developed as biological weapons because of the inherent infectious characteristics that readily enabled such organisms to serve as weapons. However, as synthetic biology continues to expand capabilities to create and modify biological weapons, there is an increasing need for biosafety and biosecurity assurances for humans, animals, plants, and the environment. The following sections examine the current and future state of research on five categories of agents, or "platforms," that could be used as biological weapons: viruses, microbes, multicellular organisms, cell-free systems, and prions.

\subsection{Promoting Responsible Research in Modern Biotechnology: Tripwires as a Framework to Understand Red-Team Capacity and Intent for Nefarious Deployment of Technology}

States will pass through a series of broad stages on the path to developing and deploying biological weapons. There are characteristics typical of states and actors at each stage, and these characteristics can serve as tripwires to identify if a group is poised to become more or less of a biosecurity threat. We identify four stages: (1) the indication of an interest in synthetic biology, (2) the achievement of scientific, technological, and engineering capacity for synthetic biology, (3) the development or acquisition of synthetic biology weapons, and finally, (4) the deployment of 
synthetic biology weapons. Stage 1 is further broken down into top-down and bottom-up initiatives, while Stage 3 is broken down into homegrown development of weapons and acquisition from external sources.

This section concludes with a discussion on technological tripwires, or advancements in the techniques and technology used in synthetic biology which will drastically increase what people are capable of doing with synthetic biology. A summary of different tripwires can be found in Table 14.1.

\subsubsection{Regime Characteristics that Could Lead to Synthetic Biology Weapons Development and Their Tripwires}

This section provides a preliminary process model, developed through the distillation of various country profiles, of the steps leading to the deployment of synthetic biology weapons. This process model lists the outward signs a country can project in its path to weapons development, and proposes actions that might be taken to

Table 14.1 Categories and descriptions of tripwires that can be used to indicate when a nation, sub-state group, or individual is becoming more or less of a biosecurity threat

\begin{tabular}{l|l}
\hline Top-down & \multicolumn{2}{l}{ Information Hazard } & $\begin{array}{l}\text { The release of information by a nation that could be used by a malicious } \\
\text { actor, or the suppression of bottom-up information hazards }\end{array}$ \\
\hline Conflict & $\begin{array}{l}\text { Internal or external conflict that motivates a nation to develop and use } \\
\text { biological weapons to maintain power }\end{array}$ \\
\hline Public health crisis & $\begin{array}{l}\text { A natural epidemic that causes biosecurity and biosafety regulations to be } \\
\text { relaxed in search of a treatment or cure }\end{array}$ \\
\hline $\begin{array}{l}\text { Geopolitical } \\
\text { alignment }\end{array}$ & $\begin{array}{l}\text { Establishing relations with a nation that has a record of biosecurity } \\
\text { compliance or incompliance }\end{array}$ \\
\hline Bottom-up & $\begin{array}{l}\text { The release of information by an individual, company, or academic } \\
\text { institution that could be used by a malicious actor }\end{array}$ \\
\hline Information Hazard & $\begin{array}{l}\text { The perception that money can be made through the use of synthetic } \\
\text { biology }\end{array}$ \\
\hline Profit motivation & $\begin{array}{l}\text { Joining with a high or low biosecurity threat entity in new partnerships, } \\
\text { mergers, or research consortia }\end{array}$ \\
\hline Partnership & Synthesis of nucleotides into the desired sequence \\
\hline $\begin{array}{l}\text { Technological } \\
\text { synthesis }\end{array}$ & $\begin{array}{l}\text { Assembling multiple smaller fragments of oligonucleotides into the } \\
\text { desired larger sequence }\end{array}$ \\
\hline DNA assembly & Editing and inserting desired sequences into targeted sites of a genome \\
\hline $\begin{array}{l}\text { Genetic } \\
\text { modifications }\end{array}$ & $\begin{array}{l}\text { Designing and producing proteins and other biomolecules in a laboratory } \\
\text { with natural or unnatural parts }\end{array}$ \\
\hline Protein engineering
\end{tabular}




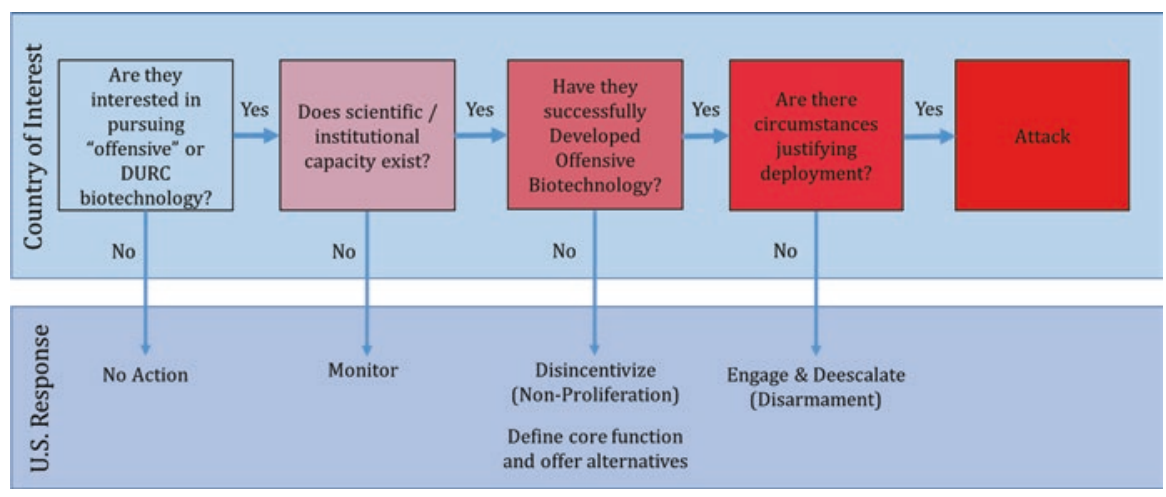

Fig. 14.1 Demonstrative synthetic biology biosecurity event tree

engage with countries at each stage of the process. Figure 14.1 shows an example process model, in the form of an event tree, which might be used by the US.

This section also lists potential tripwires that can be used to identify when a country is moving into a new stage and becoming more or less of a biosecurity threat. These can include alterations in a nation's (a) incentives to engage in DualUse Research of Concern (DURC), (b) degree of security and control over institutional and individual activity in the synthetic biology space, and/or (c) potential for a militarization of synthetic biology and its enabling technologies.

\subsubsection{Stage 1a. Bottom-Up Initiative: Independent Actors Indicate Interest in Synthetic Biology}

Corporate, academic, and other non-governmental actors may have incentives to pursue the development of synthetic biology. In this stage of the process model, the economic incentives can indicate the value of various non-weapon applications of synthetic biology, including in the fields of energy, pharmaceuticals, agriculture, and medical applications. Thus, any monitoring of the synthetic biology domain during this stage will require an understanding of any influential economic fields that could benefit from synthetic biology development, particularly fields with high Dual-Use Research of Concern (DURC) applicability. Profit motivation is a large tripwire for signaling a bottom-up interest in synthetic biology. If individuals or institutions perceive that a profit can be made through the use of synthetic biology, then they are more likely to become interested.

Bottom-up actors interested in developing synthetic biology may also be responding to an impetus other than economics. For example, academics who studied abroad may wish to continue their research by opening a synthetic biology laboratory in their home country. Without the direct input of the government, bottom-up development is more likely to be directly related to the ambitions and profits of small academic or commercial entities, both of which have low incentives to 
prioritize weapons development and high incentives to be transparent about their work (especially during the beginning stage when they might be acquiring important partners or support).

Information hazards are a tripwire to watch for groups moving from an interest in synthetic biology to achievement of synthetic biology capabilities (Stage 2). An information hazard can be defined as: "A risk that arises from the dissemination of (true) information that may cause harm or enable some agent to cause harm." Such a hazard may arise through data spillage of classified and/or sensitive information related to scientific and/or technological capabilities to acquire, engineer, test, and/ or build DURC-related research and products. Typically, an information hazard is seen as the "critical cornerstone on the bridge from inspiration to actualization" of a biological weapon or harmful engineered biological product (Esvelt 2018; Kirkpatrick et al. 2018).

In order to address this, some countries have a strong culture of "self-governance," whereby teams of scientists proactively tackle DURC concerns before, during, and after the completion of a research project. However, other states (in particular, many East Asian and Southeast Asian nations) lack this custom, instead expecting biosecurity management to come from powerful government officials who have limited knowledge of or expertise in the research being performed. The publication of DURC with little legitimate commercial and/or social utility (i.e., the recombination of extinct human pathogens) should be monitored, and actions to reduce the occurrence of such publication should be taken at the institutional, editorial, or state level. New partnerships or mergers between companies and/or universities, or the creation of research consortia, the membership of which comprises representatives from multiple nations, could indicate the risk of a bottom-up information hazard leading to a nation gaining synthetic biology capabilities. Monitoring should be conducted to see if the new partnerships or mergers include members who would increase biosecurity (e.g., watchdog NGOs and/or participants with an established record of compliance with the BWC) or decrease it (e.g., participants with a record of noncompliance).

Countries currently developing bottom-up initiatives in synthetic biology include Iran, where academics have begun attending international topical conferences, Saudi Arabia, where the King Abdullah University has a program in synthetic biology, and Ukraine, where several universities offer coursework in synthetic biology.

Bottom-up initiatives in synthetic biology do not indicate a lack of support from the governing regime, only a lack of coordinated efforts. Bottom-up initiatives can also provide impetus for top-down initiatives (Step 1b).

\subsubsection{Stage 1b. Top-Down Initiative: Regime Indicates Interest in Synthetic Biology}

A coordinated top-down effort to support synthetic biology research can emerge from a governing regime independent of whether bottom-up activities are already occurring. Because synthetic biology is a DURC technology, any regime publicly 
signaling its interest in developing synthetic biology capabilities has potentially taken an early step on the path of synthetic biology weapons development. The funding and other incentives made available could hypothetically be used to direct research in a way that benefits the government itself, including through weapons development. However, many products of synthetic biology are not and cannot be used as weapons: interest in synthetic biology does not necessarily indicate nefarious intentions or the desire to develop a weapons program. Accordingly, the economic context of research ambitions and their relationship with other regime ambitions is highly relevant to any evaluation of the government's intentions. Monitoring of countries in this stage should relate the synthetic biology ambitions of the regime to other stated ambitions, such as exports they may seek to expand. In this way, profit motivation is also a top-down tripwire for indicating when a regime is likely to become interested in pursuing synthetic biology.

Information hazards are also an important tripwire for a top-down initiative moving from interest to capacity. For synthetic biology, Esvelt and Kirkpatrick et al. note the importance of states as protectors against information hazards that could inspire rogue militaries, terrorist groups, companies, or even individuals to learn and pursue synthetic biology research. Increasingly, however, the capacity for centralized governments to regulate biosecurity information hazards is becoming prohibitively difficult due to the globalized and increasingly diversified nature of synthetic biology research (Trump et al. 2020).

\subsubsection{Stage 2. Achievement of Scientific, Technological, and Engineering Capacity for Synthetic Biology}

Following an expression of interest and subsequent investment in synthetic biology, groups or individuals within a country may successfully develop synthetic biology applications. During this stage of synthetic biology development, monitoring should occur. Academic publications as well as commercial patents, products, and processes are worthy of being monitored, as they can all facilitate greater understanding of a country's internal synthetic biology capabilities. Exchanges of human capital are another source of information, though this may be more difficult to observe or monitor, especially within corporate structures. It is, however, possible that although corporate profit motivations cause actors to conceal specific details of their work, the overall capabilities are still evident in the final products.

Tripwires that would indicate a country at this stage as being more or less of a biosecurity threat include public health crises and geopolitical alignment. Public health crises can take the form of epidemics, sustainability crises, pollution, or other events where public health is directly threatened by a catalyst. Whether targeting humans, animals, crops, or the natural environment, epidemics represent the most visible and urgent of public health crises relevant to biosecurity. In such crises, states are incentivized to bend or relax established rules and norms regarding biological safety in search of vaccines, treatments, and cures for the disease. Such a relaxation of biological safety standards could become a biosecurity concern. The 
pressure and financial incentives to foster interventions for public health crises can drive institutional actors to ignore biosecurity rules, share sensitive information that may be applied to DURC, or otherwise facilitate the development of DURC products and materials that would otherwise, in non-emergency situations, be more closely scrutinized.

Geopolitical alignment refers to the alliances, agreements, or participations to which a state voluntarily commits itself. The development of shared scientific research or collaborative agreements between states can signal movement in the strength of a state's biosecurity intentions and enforcement capabilities, both directly and indirectly. Tripwires relating to geopolitical alignment include direct participation within collaborative security agreements like the BWC, which would indicate a state's biosecurity threat is reduced, or indirect partnerships with other states that have a strong or weak biosecurity record. The potential increased capabilities and reduced biosecurity-biosafety standards indicated by this tripwire represent a hazard that can benefit non-state actors as well.

During this stage, monitoring should encompass laboratory construction, whether private, academic, or governmental, with special attention to features in construction that suggest clandestine laboratory spaces, as well as any synthetic biology funding sources and their disbursements. The exchange of human capital between countries with different competence levels can help indicate the direction of research and future capabilities, and the quality of both bottom-up and top-down biosecurity initiatives will reveal the ease with which researchers could skirt biosecurity guidelines, regulations, and laws for their own benefit. Finally, the published outputs and marketed products will provide insight into the level of synthetic biology capabilities within the country. Economic incentives, including potential clients for weapons exports, should continue to be monitored.

\subsubsection{Stage 3a. Active Development of Synthetic Biology Weapons}

Once competence in synthetic biology is achieved, it is possible that some synthetic biology research may be directed into national laboratories for state-funded weapons development purposes. These laboratories do not have the same transparency practices as academic or corporate actors, and it should be assumed that such weapons development will not be reported to the international community. Monitoring of countries in this stage may include tracking the flow of experienced human capital from for-profit or academic sectors into government sectors, with special attention to gaps or abrupt decreases in publications. This could indicate clandestine synthetic biology development under regime funding, which could indicate offensive purposes.

Additionally, independent actors may pursue weapons development outside of their government institutions, if provided the correct incentives by patrons. Given access to sufficiently powerful technology, independent actors may harness it for nefarious purposes if the benefits would be useful or worthwhile to them and exceed the benefits of abiding by existing biosecurity frameworks. Similarly, profit 
motivation could also lead countries and sub-state actors to develop biological weapons at the behest of a partner nation or client, making profit motivation a tripwire for entering this stage.

A state's record of internal strife and recent or ongoing external conflict can be used as another tripwire for a state or sub-state actor's willingness to develop a synthetic biology weapon or to move to Stage 4, the deployment of such a weapon. While a past record of such conflict can help characterize a state's likelihood to embrace biological weapons, its position in ongoing or potential conflict in the near term serves as an especially significant tripwire of concern. External conflict, or active combat between two or more states, is a tripwire of concern as it incentivizes a government to pursue force multipliers or scientific innovations that will provide an edge in combat. Such a tripwire is particularly enticing for middle income states that are currently fighting or may fight a state of comparable or even superior power. For example, Iraq under Saddam Hussein deployed chemical weapons against poorly-armed yet highly-motivated and organized Iranian forces (Ali 2001; Szinicz 2005). Iraq increased its use of unconventional weapons as the war dragged on and as conventional Iraqi armor, aircraft, machines, and weaponry were exhausted.

For external conflict, biological weapons represent (a) a first-strike capability, capable of crippling enemy health, armor, or agriculture, (b) a force multiplier, capable of providing an edge against a near evenly-matched foe, or (c) a survival mechanism to attack an enemy who has the upper hand in a conventional war, where the losing party becomes increasingly desperate to fend off attacks and ensure survival. Internal conflict includes, among other scenarios, civil war, riots, and other forms of civil strife or internal dissension. Chemical and biological weapons have been considered and/or deployed as a means of (a) instilling fear and control over parties in dissent against the regime, or (b) as a force multiplier to inflict mass casualties against an overwhelming rebellious force. As an example of (a), the government of Syria - which began to seek unconventional weapons in the 1990s - deployed chemical weapons as Syrian Government forces began to lose ground in the Syrian Civil War (Eisenkraft and Falk 2019; Diab 1997). An example of (b) is the apartheid government in South Africa's active development, testing, and deployment of biological weapons to assassinate key anti-government figures and to serve as a weapon of last resort to quell a mass revolt against the government (Hay 2016).

Monitoring efforts for countries in this stage may include monitoring imports, exports, information transfers, and general geopolitical relationships with other governments, especially those engaged in belligerence elsewhere, either domestically or internationally. Efforts should also include monitoring whether a state or non-state actor has or will be challenged by a powerful force against which conventional armaments may be insufficient to ensure survival, or if there is the potential for widespread civil strife or civil war. Sufficient indications of clandestine synthetic biology development at this stage may necessitate active interventions rather than passive monitoring, though the monitoring specified in Stage 2 should also continue. Interventions could include overtures to encourage the state to join international biosecurity efforts like the BWC and UN Resolution 1540 if it has not done so already, or to submit to routine or supplemental monitoring according to the 
circumstances. There are currently no countries that have publicly admitted to pursuing or possessing synthetic biology weapons capabilities.

\subsubsection{Stage 3b. Acquisition of Synthetic Biology Weapons from an External Source}

Countries or non-state actors without synthetic biology capabilities may choose to forgo developing domestic technological capabilities if they are able to acquire synthetic biology weapons through other avenues. This requires access to competence elsewhere, either through existing relationships or through building new ones. Regimes possessing advanced technological capabilities may attract actors with inclinations to learn and then use these capabilities for violence, as was the case with the 9/11 hijackers who trained in U.S. flight schools.

With DURC technologies, weapons development can arise inadvertently through exploration of beneficial uses for innovations. In contrast, actors willing to invest only in weaponized outputs signal a lack of economic interest in peaceable applications for the technology, and for this reason their interest in the weapons applications may indicate a stronger propensity to ultimately deploy them. However, such weapons could also serve as a tool of deterrence against another regime, though this would necessitate publicizing capabilities at some point.

It may be difficult to determine when an actor who is aiming to purchase synthetic biology weapons ultimately acquires them. However, regardless of how far along in the process of acquiring these weapons an actor is, situation monitoring can entail disincentives for armament, whether economic assistance or coercive or offensive actions. Such actors may be best identified through their relationships with competent synthetic biology developers, whose outputs, collaborators, and clients should already be being monitored according to Stage 2. If a particular vendor appears to be on the cusp of selling a weapon, engagement can involve encouraging the vendor to increase their biosecurity processes as well as public engagement with the deal, since the public may be uncomfortable with selling synthetic biology weapons, especially to the type of belligerent actors likely to seek them.

\subsubsection{Stage 4. Deployment of Synthetic Biology Weapons}

Whether weapons are produced domestically or acquired from external sources, an instigating event will likely need to occur before their deployment. History abounds with examples of events that have triggered offensive actions, including both acute events (the secession of the Confederacy, which started the US Civil War) and chronic events that built over time (as resistance to the Assad regime of Syria mounted, the regime deployed chemical weapons). The nuclear bombs that ended World War II in the Pacific were part of a larger Allied strategy, but the timing of the deployment was more determined by weapons development (Stage 3a) within an extended conflict than a single precipitating factor. Still, even if there is not an acute 
precipitating event, a regime considering deploying weapons must both have capability and a belligerent relationship with another entity. Thus, any regimes already under surveillance or being engaged according to Steps 2 and 3 should be further engaged in the event of a conflict erupting.

We propose a specific profile for actors at risk of deploying synthetic biology weapons, which can constitute a means to identify them and evaluate their risk levels. In addition to their geopolitical alignment, which determines whether they have access to the weapons and a reason to deploy them, such actors are likely to be fairly risk tolerant because the spatial and temporal effects of a synthetic biology attack are not currently well-understood. Non-scientist citizens are often averse to new, potentially harmful technologies, and regimes that give those citizens more voice in governance risk paying a high price for such weapon deployment. Citizens from regions that have already suffered the ill effects of scientific advancements may be especially averse to deployment. For example, Ukrainians and Belarussians, who were especially negatively affected by the Chernobyl disaster, and Kazakhis, who have suffered from above-ground nuclear testing sites, may be particularly averse when it comes to the deployment of shadowy, poorly-understood novel weapons. Similarly, countries exhibiting cautionary principles towards genetically modified organisms will be less likely to resort to synthetic biology weapons because of preestablished risk aversion.

However, the opinions of the population only matter if the regime in possession of the weapons is answerable to that population. A risk-tolerant regime may be one characterized more by authoritarianism than democracy, or it may be a group of non-state actors without demarcated constituents. Therefore, one metric to estimate the probability of synthetic weapons deployment could arise from examining a regime's political participation and human rights record, which indicates its ability to ignore or dehumanize segments of the population. Another metric may be whether the regime's rhetoric somehow presents itself as insular and separate from the targets of a potential weapons deployment. Reality is frequently subservient to perception, and in moments of high stress, actors who do not answer to a larger and more moderating population and are accustomed to dehumanizing their adversaries may deem the benefits of synthetic biological weapons to be worth the uncertain risks. Therefore, there is a spectrum of likelihood in weapons deployment that depends on various factors beyond weapons possession. Finally, decision makers will weigh these factors against the magnitude of the damage they anticipate if the weapon is not deployed. If they are facing a real or perceived existential threat, they may see no reason for restraint.

Should events proceed to the point where a regime considers launching a synthetic biological weapon, active engagement will be urgently needed. This could include attempts to physically compromise the weapon and the deployment infrastructure, or diplomatic efforts that assure the regime of a sufficiently positive outcome to its conflict without launching the weapons. The latter strategy resembles that used by the US during the 1973 Arab-Israeli War, in which the US quickly intervened on Israel's side in order to sway the tide after Israel threatened to use nuclear weapons. Ideally, such a last-ditch effort would only be necessary after the 
failure of many other efforts to diminish synthetic biology weapons capacity starting from the time when the actor in question entered hostilities with another entity. This also raises the possibility that governments might threaten to deploy synthetic biology weapons in order to receive assurances. In these cases the information gleaned from earlier monitoring should be able to inform the actual veracity of the threat. Additionally, if sufficient actions are taken in earlier stages of weapons development, such a situation should not arise.

\subsubsection{Key Enabling Technologies and Technological Tripwires}

Many enabling technologies are key to further progress in synthetic biology. Just as synthetic biology enables potential misuse with dual-use studies or technologies, developments in the technologies or techniques outlined below also allow for dramatic growth of potential security threats by expanding the capabilities of synthetic biology, and therefore the abilities of actors. Understanding the key breakthroughs needed for the expansion of synthetic biology capabilities is necessary for regulatory agencies to anticipate and respond to potential and imminent threats. If regulatory agencies are aware of the relevant technologies and where key breakthroughs are likely to occur, signs of advancements in these technologies can act as tripwires and signal to defense agencies when new threats have emerged due to the nowenhanced capabilities of synthetic biology and malicious actors. It is important to note that as with nearly all aspects of synthetic biology, enhanced synthetic biology capabilities are not in and of themselves normatively "bad"; they will overwhelmingly be put to beneficial uses. However, such technological advancements will also open the door to the creation of more complex or novel biological weapons that aren't possible with today's technology, and thus these advancements should be monitored so that novel types of biological weapons can be continually anticipated and defended against as they are developed.

It is also critical to acknowledge the increasing usage and development of computing power and Artificial Intelligence (AI) in scientific advances. Synthetic biology harnesses these resources to improve many different aspects of product production, including fidelity and automation. With major advances in computing and AI, the capabilities of synthetic biology will also expand. While not explicitly mentioned above as a technological tripwire, computing power serves as an undercurrent of development that cannot be ignored. Advances in these particular fields will produce the most radical changes in synthetic biology capabilities and can thus most easily serve as tripwires for observing the capacities of synthetic biology as a whole and subsequently the capabilities of any "malicious actors." 


\subsection{Conclusion}

Building an effective biosecurity strategy to encompass twenty-first century synthetic biology requires understanding the novelties synthetic biology creates in the biosecurity threat space, as well as the structural vulnerabilities it can exploit and the likely causes of inadequate biosecurity practices. Tripwires can be helpful in alerting monitoring groups and governments as to potential biosecurity threats. Synthetic biology's novel biosecurity concerns arise from its broad scope, wider availability, complexity, and uncertainty over current and future capabilities. Critical developments such as gene editing via CRISPR vastly improve upon previous genetic engineering processes and may yield a revolution in human and environmental health research, but may also cause substantial and irreversible harms.

Harms may also arise through the deliberate use of such techniques to disrupt human and environmental systems. Misuse of synthetic biology techniques requires two circumstances: (a) the spread of ideas, techniques, or knowhow to utilize synthetic biology's enabling technologies for irresponsible or nefarious purposes ("information hazard"), and (b) the ability to use such knowledge and tools to generate and disseminate harmful engineered organisms to vulnerable recipients. The tripwires we have outlined in this chapter aim to signal when these necessary circumstances have been or are close to being reached.

Synthetic biology advancements have already included the publication and dissemination of a methodology for synthesizing horsepox in a laboratory setting. Some critics say this information could support a nefarious actor to reconstitute and develop smallpox, or to synthetize other viruses. Additionally, the widely publicized recreation of the 1918 Spanish Influenza, which killed some 50 million people worldwide at the close of World War I, could facilitate the synthesis process for actors wishing to cause harm (Tumpey et al. 2005). Even nonpathogenic approaches have been defined as dual-use research, ranging from the disruption of local ecologies via gene drives to the manipulation or destruction of inorganic materials.

These and dozens of other cases demonstrate the increasing ease by which an actor can acquire information and apply existing tools to deploy advanced genetic engineering applications with limited to no oversight. In 1975, the U.S. National Institute of Health (NIH) established compliance measures for genome engineering that were enforced through funding restrictions; however many synthetic biology innovators in the US can now operate without NIH funding, approval, or even awareness, and the NIH does not oversee research in other countries. Today, the financial costs, time limitations, and skill requirements needed to wield synthetic biology tools have scaled down to become accessible even to high school students. Furthermore, the required baseline knowledge will further diminish over time as synthetic biology processes become more streamlined. While such broad access to sophisticated genetic engineering knowledge and equipment can accelerate scientific breakthroughs, it also places the responsibility of biosecurity on a huge number of unsupervised actors across the globe. 
In 2018, the states-parties to the BWC noted that increased access to technologies such as gene editing, gene drives, and gene synthesis is being conferred to actors with limited or no oversight from established industry or governmental organizations, raising concerns about potential violations of the BWC. It is helpful to forecast and understand looming threats and potential mitigation strategies at various scales, but international treaties are not structured to oversee bottom-up efforts related to the localization and globalization of synthetic biology below the national scale. One response may be the broadening of engagement from traditional oversight agencies like NIH. Where top-down governance proves insufficient, other actors such as universities, non-profits, and companies will need to engage their gatekeeping and watchdog capabilities to protect against nefarious actors. Topdown governance may support such initiatives, which will require harmonization and communication up to the international level. Tripwires, in the form of a game theoretic approach, can be critical in identifying the range of timelines whereby nefarious deployment of biotechnology becomes realistic and actionable.

Using the lens of risk analysis, longstanding biosecurity policy practices appear to have produced gaps in biosecurity effectiveness for synthetic biology. These policies include (a) the framing of security as a cost or undesirable expense to be minimized, (b) the siloing of scholarship and practice across disciplinary domains and between academia, government, industry, and civil society, and (c) the narrow framing of security issues that ignore technological developments occurring within a number of different countries, by new actors, and/or in adjacent technology fields. Each of these concerns could be addressed by policy solutions that both support technological development and mitigate security threats while facilitating public engagement in synthetic biology and investment in its products as they enter the marketplace. Policies for synthetic biology must be scalable, transferable, and adaptable in order to address its emerging technical and social challenges.

Advanced biological research is no longer overwhelmingly dominated by Europe and the US, and this may introduce different approaches to or priorities for biosecurity. For instance, Russia's Federal Research Programme for Genetic Technologies Development for 2019-2027 intends to "implement a comprehensive solution to the task of the accelerated development of genetic technologies, including genetic editing; to establish scientific and technological groundwork for medicine, agriculture and industry; to improve the system of preventing biological emergencies and monitoring in this area." Similarly, Saudi Arabia is funding research related to the development of microbial cell factories to produce fuels and chemicals. Meanwhile, the Singaporean government is investing considerable resources into the funding of life and environmental sciences research at Nanyang Technological University, the National University of Singapore, and the Agency for Science, Technology and Research (A*STAR). The Chinese Academy of Sciences is establishing an Institute of Synthetic Biology, which is tasked with the dual responsibilities of fostering roadmaps for the future development of Chinese synthetic biology while also establishing safety and security norms for researchers at Chinese institutions. There are no top-down efforts beyond existing mechanisms like the $\mathrm{BWC}$ or the $\mathrm{CWC}$ to 
standardize global governance and usage of synthetic biology, and bottom-up efforts are not coordinated in their reach or messaging.

Relative newcomers to synthetic biology development may possess differing tolerances and constructions of risk than more established technology developers. The implications, though vast, can be grouped into two general areas. One includes diverging safety and security practices at various points of an international supply chain that forms the backbone of an increasingly globalized economy. Another includes the potential for small-scale experiments or national biosecurity policies to escape a given actor's control and spill across political boundaries. While one country may find the environmental risk of a particular synthetic biology application acceptable, its spread across borders into another country may disrupt those local ecologies (i.e., crashing or hardening a particular species through genetic engineering) or expose vulnerable human populations to irreversible consequences without options for amelioration. The nature of certain synthetic biology applications (i.e. gene drives) makes it impossible for risk averse countries to wholly quarantine themselves from exposure to harms resulting from another country's decisions. This is also an issue of equity because risk-tolerant countries will reap the rewards when beneficial technologies emerge, but risk-averse countries may be forced to bear their neighbors' risks without any means to capture potential rewards.

An environment of competing and incongruent risk architectures causes individual states, organizations, or industries to arrive at differing definitions of security threats or acceptable levels of loss in pursuit of a technology's intended gains. For a technology as uncertain as synthetic biology, this policy divergence may set governments, companies, and other research organizations down vastly differing policy paths, and impede consensus in assessing the minutiae of technical risk concerns or assessment protocols, or ensuring security for anyone.

Effective global biosecurity will not happen quickly, nor will it be enthusiastically adopted by all national governments or non-governmental organizations. Incentives to misuse synthetic biology with harmful consequences remain high for certain negligent actors, as are the incentives to dual-use by nefarious actors, and the coming years may see such misuse affecting human or environmental health. Successful biosecurity implementation must be adaptable to quickly incorporate uncertainty as well as new capabilities. Urgent steps are required to place such notions into practice before a major threat incident, both to prevent the damage incurred by such an incident and to avoid subsequent policy changes which could limit or ban platforms of synthetic biology research entirely. Besides forgoing the benefits of the technology, such a ban could force development underground and further out of the reach of coordinated governance or risk assessment. By identifying the social, economic, institutional, and technological tripwires that influence a state's trajectory towards biosecurity research of concern, responsible parties can take steps to apply biosecurity to maximize technological benefits while minimizing its dual-use potential. 


\section{References}

Ahteensuu M (2017) Synthetic biology, genome editing, and the risk of bioterrorism. Sci Eng Ethics 23(6):1541-1561

Ali J (2001) Chemical weapons and the Iran-Iraq war: a case study in noncompliance. Nonproliferation Rev 8(1):43-58

Biological Weapons Convention (1972) United Nations

Department of Justice (2010) Justice Department and FBI announce formal conclusion of investigation into 2001 Anthrax attacks. Press release, February 19. https://www.justice.gov/opa/pr/ justice-department-and-fbi-announce-formal-conclusion-investigation-2001-anthrax-attacks

Diab MZ (1997) Syria's chemical and biological weapons: assessing capabilities and motivations. Nonproliferation Rev 5(1):104-111

Eisenkraft A, Falk A (2019) The use of chemical warfare agents during the Syrian Civil War. In: Chemical warfare agents: biomedical and psychological effects, medical countermeasures, and emergency response. CRC Press, Boca Raton, p 103

Ellis R (2014) Creating a secure network: the 2001 Anthrax attacks and the transformation of postal security. Sociol Rev 62(1):161-182. https://doi.org/10.1111/1467-954X.12128

Esvelt KM (2018) Inoculating science against potential pandemics and information hazards. PLoS Pathog 14(10):e1007286

Evans NG, Selgelid MJ (2015) Biosecurity and open-source biology: the promise and peril of distributed synthetic biological technologies. Sci Eng Ethics 21(4):1065-1083

FBI. Amerithrax or Anthrax Investigation. https://www.fbi.gov/history/famous-cases/ amerithrax-or-anthrax-investigation

Franconi R, Illiano E, Paolini F, Massa S, Venuti A, Demurtas OC (2018) Rapid and low-cost tools derived from plants to face emerging/re-emerging infectious diseases and bioterrorism agents. In Defence against bioterrorism. Springer, Dordrecht, pp 123-139

Getz LJ, Dellaire G (2018) Angels and devils: dilemmas in dual-use biotechnology. Trends Biotechnol 36(12):1202-1205

Greer SL, Trump B (2019) Regulation and regime: the comparative politics of adaptive regulation in synthetic biology. Policy Sci 52:1-20

Gronvall G (2015) Biosecurity: the opportunities and threats of industrialization and personalization. Bull At Sci 71(6):39-44

Gronvall G (2018) The security implications of synthetic biology. Survival 60(4):165-180

Hay A (2016) The South African biological warfare program. In: Biological threats in the 21st century: the politics, people, science and historical roots. World Scientific Publishing, Singapore, pp 137-158

Kirkpatrick J, Koblentz GD, Palmer MJ, Perello E, Relman DA, Denton SW (2018) Editing biosecurity: needs and strategies for governing genome editing. George Mason University, NATO SPS ARW, July 2019

Ledford H (2010) Garage biotech: life hackers. Nat News 467(7316):650-652

Mayor A (2003) Greek fire, poison arrows \& scorpion bombs: biological and chemical warfare in the ancient world. Overlook Duckworth, Woodstock

Noyce RS, Lederman S, Evans DH (2018) Construction of an infectious Horsepox virus vaccine from chemically synthesized DNA fragments. PLoS One 13(1):e0188453

Szinicz L (2005) History of chemical and biological warfare agents. Toxicology 214(3):167-181

Trump BD, Cummings CL, Kuzma J, Linkov I (2020) Synthetic biology 2020: frontiers in risk analysis and governance. Springer, Cham

Tumpey TM, Basler CF, Aguilar PV, Zeng H, Solórzano A, Swayne DE, et al (2005) Characterization of the reconstructed 1918 Spanish influenza pandemic virus. Science 310(5745):77-80

Yeh JY, Seo HJ, Park JY, Cho YS, Cho IS, Lee JH, et al (2012) Livestock agroterrorism: the deliberate introduction of a highly infectious animal pathogen. Foodborne Pathog Dis 9(10):869-877 
Open Access This chapter is licensed under the terms of the Creative Commons Attribution 4.0 International License (http://creativecommons.org/licenses/by/4.0/), which permits use, sharing, adaptation, distribution and reproduction in any medium or format, as long as you give appropriate credit to the original author(s) and the source, provide a link to the Creative Commons license and indicate if changes were made.

The images or other third party material in this chapter are included in the chapter's Creative Commons license, unless indicated otherwise in a credit line to the material. If material is not included in the chapter's Creative Commons license and your intended use is not permitted by statutory regulation or exceeds the permitted use, you will need to obtain permission directly from the copyright holder. 